\title{
Worldwide assessment of healthcare personnel dealing with lymphoedema
}

Henrike Schulze ${ }^{1 *}$, Marisa Nacke ${ }^{2}$, Christoph Gutenbrunner ${ }^{1}$ and Catarina Hadamitzky ${ }^{3}$

\begin{abstract}
Background: Lymphoedema is a pandemic with about 250 million people suffering from this condition worldwide. Lymphatic diseases have considerable public health significance, but yet few professionals are specialised in their management causing a substantial burden on health resources.

Aims and objectives: This study aims to give an overview of the approximate number of medical professionals, professional societies, institutions and companies dealing with lymphoedema in various countries. Concepts of improvement for current human resources are considered.

Methods: An online database analysis (Google search engine and PubMed) was carried out for each country of the world. Additionally, relevant congress participant lists as well as member lists of significant medical societies and reports of the World Health Organisation were analysed.

Results: Overall distribution of tertiary level professionals specialised in this field is heterogenous. A decrescent gradient of professionals can be seen between developed and developing countries and between urban and rural areas. Countries in general do not seem to have yet met the current demand for specialists at tertiary level in this field.

Conclusions: This study intends to draw attention to the current medical coverage gaps due to a low number of lymphoedema specialists at tertiary level. It wishes to start a discussion about structured reimbursement and certification of knowledge and skills that are essential incentives for experts to act as multiplicators and change the lack of care in the mid-term. Current fail prescriptions and evitable disability and sick certificates represent a high financial burden that could be reinvested in a correct management. Policy makers must focus in the two above mentioned essential measures. Medical training and the consequent development of the industry will then naturally take place, as it was the case for other professional groups in the past.
\end{abstract}

Keywords: Lymphology, Lymphoedema, Lymphatic diseases, Medical healthcare resources, Medical education

\section{Background}

Lymphoedema, also known as elephantiasis, is a chronic disease characterised by massive swelling of limbs or tissues. The disease affects about 250 million patients worldwide [1]. It occurs through accumulation of fluid and other tissue elements that would normally be drained by the lymphatic system. The origin can be genetic or, more commonly, secondary to injuries.

Secondary causes of lymphoedema vary according to geographic distribution [2]. In developing countries, it is

\footnotetext{
* Correspondence: henrikeschulze@hotmail.de

${ }^{1}$ Clinic of Rehabilitation Medicine, Hannover Medical School,

Carl-Neuberg-Straße 1, 30625 Hannover, Germany

Full list of author information is available at the end of the article
}

often a corollary of parasitic infections through Filaria or Loa Loa or caused by Podoconiosis and has massive global public health significance [3].

In developed countries, secondary lymphoedema mainly occurs after cancer therapy [4]. It is strongly associated with prevalent cancer types, e.g. breast or prostate cancers [5]. Depending on the type and extent of treatment, the anatomic location, the heterogeneity of assessment methods, and the follow-up, the reported incidence of cancer-related lymphoedema varies $[6,7]$. Because lymphatic swelling can occur decades after cancer treatment, cancer patients undergoing lymph node dissection should be considered at lifetime risk. 
Despite its epidemiological relevance, only few professionals are specialised in the management of lymphatic diseases [8-10]. Lymphology is a mostly overlooked field in medical schools and exposure of medical professionals to this field varies greatly [10,11]. The lack of professional knowledge especially at the level of general practitioners, as first medical contacts, is considered to be a problem that impacts early detection, leads to misdiagnosis and inappropriate treatment and results in poor management of health resources $[9,10,12-17]$. Natural exacerbation of the swelling causes increased demand on healthcare resources but can also lead to life threatening infections as well as psychosocial exclusion followed by a diminished quality of life or even depression [18-21].

Appropriate management of lymphoedema, including surgical procedures, can cure the condition in $30-40 \%$ of the cases [22] but also conservative therapy with manual lymphatic drainage and compression leads to an improvement of patients' quality of life and increases their presence at work [23, 24]. Although the number of healthcare professionals specialised in lympho-vascular diseases seems to be insufficient, this phaenomenon has been left unquantified until now. In the literature of the last decade only a single publication [13] directly addresses the discrepancy between offered and demanded services in this field of healthcare. Nevertheless, medical professionals could improve the current healthcare situation through their multiplication characteristics by influencing the interdisciplinary work with nurses and/or physiotherapists regarding the chosen therapy and by spreading rare knowledge in universities, hence promoting research. Empowerment of future generations could create a stronger relationship between the local health services and lymphoedema patients in the future [25].

The objective of this study was to gain an overview of the approximate number of medical physicians and researchers currently dealing with lymphoedema. Another aim was to assess the ratio between healthcare professionals and general population in vast geographical areas, and this despite low numbers of specialised healthcare professionals with tertiary level of training to be found in this field of rare knowledge. Additionally, professional societies and companies associated with lymphoedema were counted in order to understand possible concepts of improvement for current human resources, as professional training and certification allow further development in this important field. Furthermore, potential policy implications such as structured reimbursement or higher public research funding were included in the discussion of this study.

\section{Methods}

In order to map medical professionals, societies, institutions and industrial companies dedicated to lymphoedema, research was performed exclusively online for each single country of the world in three independent phases. The targeted professional groups were physicians and researchers. The search included published data from 2005 to 2015 and was restricted to six languages, namely English, German, French, Spanish, Portuguese and Italian.

In the first phase, a data collection was performed with the Google search engine. For each single country name, the word lympho*edema was introduced, and the top ten listed websites were analysed. Then, these terms were successively combined with the following words: physician or medical doctor, researcher, chronic o*edema, lymphatic filariasis, podoconiosis, elephantiasis and cancer (Fig. 1). It also allowed retrieving information on professional societies and industrial companies.

In the second phase, the search was conducted with the same keywords in the PubMed database. Relevant studies from the database were identified by their titles and abstracts. In case of uncertainties, the full text was retrieved and authors and participating institutions were listed in the corresponding countries.

In the third phase, duplicates were removed. Cross analysis on congress participants listed in scientific meetings dealing with the topic of lymphatic diseases was performed and relevant reports from the WHO were analysed. If available, member lists of medical societies for lymphatic diseases were included in the analysis. The quantifications of specialised professionals were not performed on numeric data, but on the personal data available online for each expert, including affiliation, address, and fields of interest.

\section{Data extraction and analysis}

A data extraction form was developed in Excel. Individual physicians and researchers were assigned to one of the following categories depending on their main focus: surgery, conservative therapy, research, filariasis, podoconiosis and medical imaging. Their professional affiliations were recorded along with the postal and digital address. When the information was originated in research papers, experts were grouped by geographic distribution, not by paper. International research groups had their members therefore grouped separately according to their country of residence. Experts were counterchecked individually for their qualifications (medical doctors or e.g. biologists) and a Google search for data under their name was performed to assign them to a main focus as stated above. Medical societies and institutions were also sorted by country as well as main focus and likewise pharmaceutical companies (Fig. 1). The 


\begin{tabular}{|c|c|c|c|}
\hline \multirow{2}{*}{$\begin{array}{c}\text { Creation of database } \\
\text { worksheets of } \\
\text { countries worldwide }\end{array}$} & \multicolumn{2}{|c|}{ Group } & Additional Information \\
\hline & \multirow{3}{*}{\multicolumn{2}{|c|}{$\begin{array}{l}\text { Name of Physician or } \\
\text { Researcher }\end{array}$}} & Profession and Main Focus (Surgery, \\
\hline \multirow{3}{*}{$\begin{array}{c}\text { Google search } \\
\text { with specified } \\
\text { terms }\end{array}$} & & & Podoconiosis, Research) \\
\hline & & & Postal and Digital Address \\
\hline & \multirow{2}{*}{\multicolumn{2}{|c|}{ Industry Name }} & Type of Product(s) \\
\hline$\downarrow$ & & & \\
\hline $\begin{array}{l}\text { PubMed search of } \\
\text { lymphoedema } \\
\text { related literature }\end{array}$ & \multicolumn{2}{|c|}{$\begin{array}{l}\text { Professional Societies and } \\
\text { Institutions for Lymphoedema }\end{array}$} & $\begin{array}{l}\text { Main Focus } \\
\text { Postal and Digital Address }\end{array}$ \\
\hline$\downarrow$ & & & \\
\hline \multirow{2}{*}{$\begin{array}{l}\text { Review of congress } \\
\text { participants and } \\
\text { society members }\end{array}$} & $\#$ & \multicolumn{2}{|l|}{ Search Terms } \\
\hline & $\# 1$ & \multicolumn{2}{|c|}{ Country name AND Lymphoedema OR Lymphedema } \\
\hline & $\# 2$ & \multicolumn{2}{|c|}{ \#1 AND Physician OR Medical Doctor } \\
\hline \multirow{2}{*}{$\begin{array}{l}\text { Cross-referencing, } \\
\text { elimination of } \\
\text { duplicates,updating }\end{array}$} & $\# 3$ & \multicolumn{2}{|l|}{ \#1 AND Researcher } \\
\hline & $\# 4$ & \multicolumn{2}{|c|}{ \#1 AND Chronic Oedema OR Chronic E } \\
\hline & $\# 5$ & \multirow{2}{*}{\multicolumn{2}{|c|}{ \#1 AND Podoconiosis }} \\
\hline$\downarrow$ & $\# 6$ & & \\
\hline $\begin{array}{c}\text { Analysis on indivi- } \\
\text { duals, professional } \\
\text { societies and industries }\end{array}$ & $\begin{array}{l}\# 7 \\
\# 8\end{array}$ & \multicolumn{2}{|l|}{ \#1 AND Elephantiasis } \\
\hline
\end{tabular}

Fig. 1 Flowchart showing the systematic data search process including information on database structure and search terms

main findings were analysed narratively as statistical pooling was not adequate for this scoping study.

Ethics approval was not required for this study, as online information is publicly accessible and there is no reasonable expectation of privacy.

\section{Results}

The conducted research included 208 countries on six continents. Of the entirety of countries in the world, 123 countries provided online information on at least one of the researched topics (59\% of the total sample).
Activities could be mapped in twelve out of 23 countries in North and Central America; 13 out of 17 in South America; 27 out of 49 countries in Europe; 14 out of 20 countries in Oceania; 25 out of 48 Asian countries and 32 out of 51 countries in Africa.

First, the exact numbers of tertiary level professionals dedicated to lymphatic diseases were analysed (Fig. 2). As expected, their distribution is very heterogeneous, e. g. Pakistan, with a population of more than double than Germany, has only four listed professionals, the latter having 432. A high absolute number of professionals

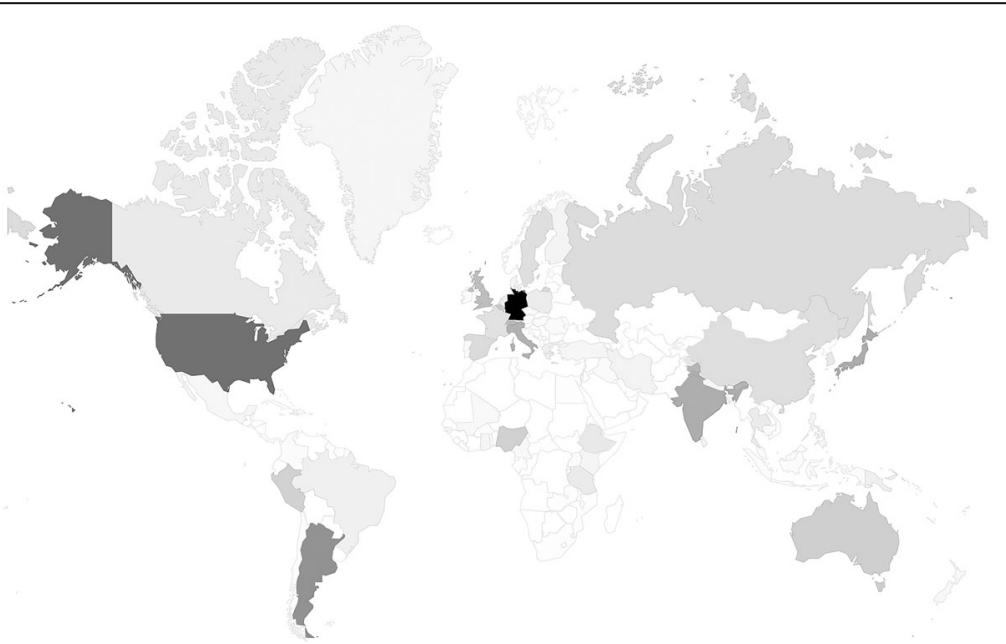

Fig. 2 Absolute distribution of professionals exclusively at tertiary level dedicated to lymphatic diseases across the world. The colour code scale shows white for zero professionals (e.g. Afghanistan or Kazakhstan) and black corresponds to the maximum number of 432 professionals found in Germany. The higher the absolute number of tertiary level professionals in a country, the darker the colour 
could be tracked in Europe $(n=1310)$ (Fig. 3a; Table 1). Whilst being the continent with the lowest absolute number of tertiary level professionals currently working in the field of lymphology, Oceania has the highest ratio of professionals per capita (165 professionals per 38.5 million people) (Fig. 3a and b, Table 1). Europe, on the contrary, displays only an average level of coverage of its population of half a billion notwithstanding the high absolute numbers of professionals. Asia, on the lower

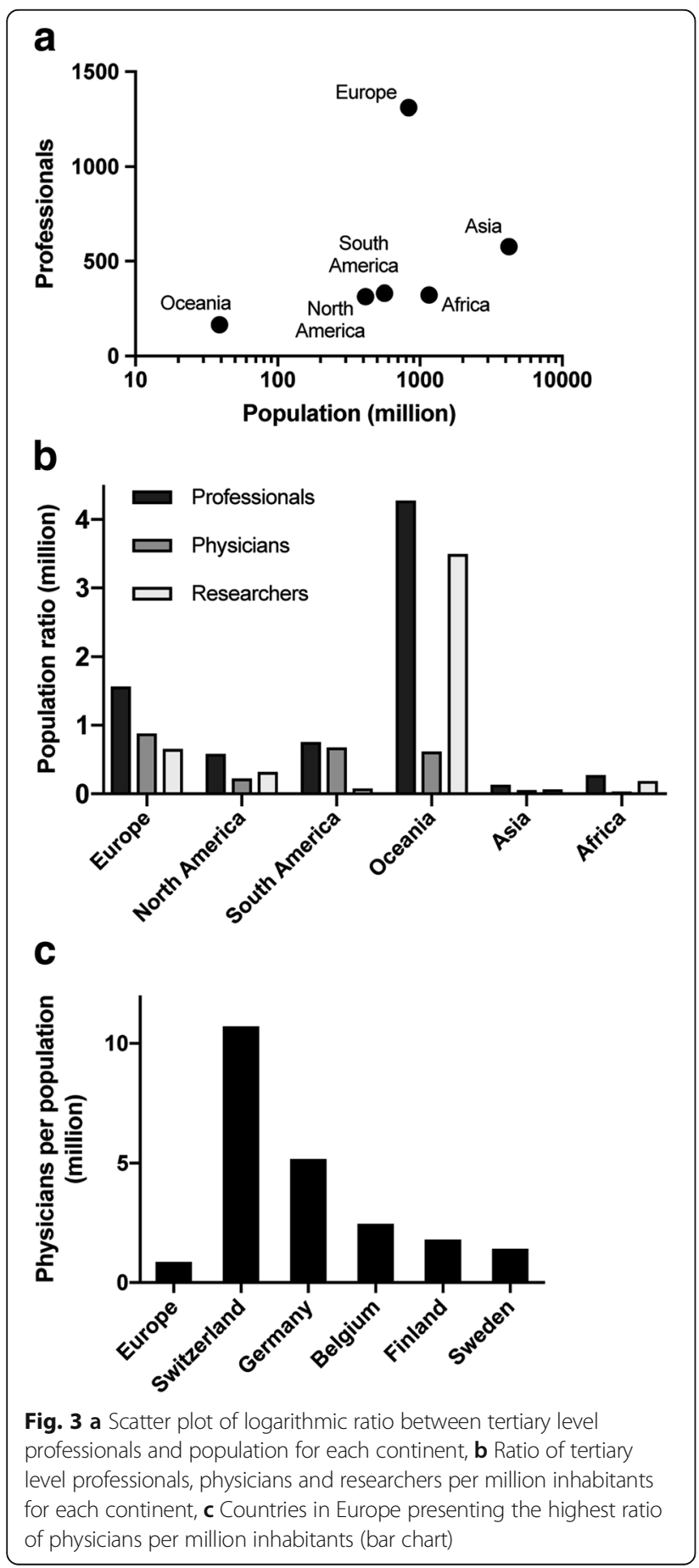

extreme, has a coverage ratio of tertiary level professionals per million inhabitants below one (Fig. 3b, Table $1)$.

Additionally, we split the focus of the tertiary level professionals into clinical activity and research (Fig. 3b; Table 1). Professionals with both foci were included in both statistics. When considering only clinically active physicians per million inhabitants, e.g. Europe had high ratios $(0.89 \mathrm{ppm})$, whereas Africa, with a total of 26 clinically active physicians, has according to our research criteria practically inexistent medical coverage in this field. Similar coverage exists for researchers in most continents excluding Oceania. Oceania has a high ratio of researchers per million inhabitants (3.5 ppm).

Also, in Europe inequality is such, that some countries presented very poor medical coverage of lymphoedema despite belonging to the European continent. Differences can already be seen comparing five European countries (Fig. 3c). Interestingly, countries with a large population such as Japan do not seem to reach the higher ratios of less populated countries like Switzerland (Table 2). The uneven distribution of tertiary level physicians was not only present at a global level, but also within single countries. Spain, with a total of 34 active physicians, can be considered a paradigm of depletion in rural areas with most physicians to be found in Madrid $(n=5)$, Valencia $(n=17)$ or Barcelona $(n=6)$ (Fig. 4).

Data regarding the specialty of physicians (Table 3) showed that most are focused on the conservative management of the disease $(n=641)$, most of them being located in Europe $(n=535)$. Concerning the operative therapy of lymphoedema, our online search was able to identify the highest number of surgeons in Europe $(n=295)$, followed by Asia $(n=139)$. Surprisingly, very few physicians are specialised in imaging procedures of lymphatic vessels $(n=64)$ despite the overlap with imaging methods used in cancer management. Concerning filarial lymphoedema, only 40 specialists could be mapped. Our search led to just two medical specialists dedicated to podoconiosis. In Asia $(n=$ $163)$ and Oceania $(n=21)$ most physicians additionally are researchers, showing a strong potential for innovation in these continents. This is also true for North America.

Our search regarding professional societies and institutions dedicated to this field of medicine showed that the leading single country is the U.S. with 161 societies (Table 4). European countries altogether have 598 societies mentioning lymphoedema as one of their points of interest, all specialties included, but oftentimes the professionals involved in these societies or institutions are the same at regional, national and international level. Additionally, some Asian countries as India are well organised in this field with a total online track of 96 Indian societies. Table 4 also shows where industrial companies dedicated to lymphoedema products are located. 
Table 1 Data for each continent for Fig. 2

\begin{tabular}{llllllll}
\hline Continent & Professionals $^{\text {a }}$ & Physicians & Researchers & $\begin{array}{l}\text { Population } \\
\text { (in million) }\end{array}$ & $\begin{array}{l}\text { Professionals/population } \\
\text { (per million) }\end{array}$ & $\begin{array}{l}\text { Physicians/population } \\
\text { (per million) }\end{array}$ & $\begin{array}{l}\text { Researchers/population } \\
\text { (per million) }\end{array}$ \\
\hline Europe & 1310 & 739 & 550 & 833.9 & 1.57 & 0.89 & 0.66 \\
North America & 332 & 128 & 182 & 562.6 & 0.59 & 0.23 & 0.32 \\
South America & 314 & 281 & 33 & 414.1 & 0.76 & 0.68 & 0.08 \\
Oceania & 165 & 24 & 135 & 38.5 & 4.28 & 0.62 & 3.50 \\
Asia & 577 & 253 & 298 & 4222.9 & 0.14 & 0.06 & 0.07 \\
Africa & 323 & 26 & 221 & 1159.8 & 0.27 & 0.02 & 0.19 \\
\hline
\end{tabular}

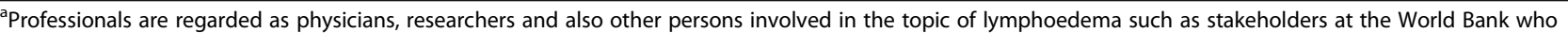
provide money for lymphoedema research and education

Leading countries are the U.K. $(n=33)$ and the U.S. $(n=$ 42). Respectively, most companies can be found in Europe $(n=90)$ and North America $(n=49)$. Developing countries are virtually depleted of industrial companies in this field, forcing them to import needed products or simply failing to provide them.

\section{Discussion}

The social burden of the lymphoedema pandemic is inversely proportional to the low number of medical professionals dedicated to its management or research. It is translated in inadequate prescriptions, poor management of health resources, as well as time of work absenteeism, social exclusion and stigma of patients $[12,18$, 19, 25-27]. The conducted study aimed at a semiquantification of the problem by showing where medical professionals can be found, and where their coverage must be expanded.

\section{Aspects of online search methods}

One possible limitation of our study resulted from restricting our search to the internet. Certainly, local offers of lymphoedema management exist that were not visible online. About $67 \%$ of the world's population does not have access to the internet [28]. Especially in developing regions patients still seek advice from traditional healers [29-35]. This is supported by reports from the Caribbean, showing that most patients only seek care from university-trained but more expensive healthcare providers when traditional treatment has shown to be ineffective [26, 27]. If patients and their communities are taught about their disease, it has been shown that a loco-cultural understanding of the disease can coexist with the biomedical one [36]. Therefore, additional lowcost programs should be established, as they improve lymphoedema outcomes, even leading to an important economic benefit as patients are able to work again or work more [24]. Examples of low-cost interventions are training of communities on hygiene measures of the lymphoedema limb as well as demonstrations for the application of topic antibiotics on secondary wound infections and bandaging. When comparing the yearly costs per patient in hygiene and/or bandaging materials including antibiotic ointments (direct healthcare costs) with the gain in working days/salary since program implementation (indirect workforce costs), Stillwaggon et al. [24] could calculate per-person savings of more than 130 times the per-person costs of their program. This demonstrates the importance of understanding the cultural background when planning health resources in these societies [37]. The online selection bias might nevertheless have the advantage of listing only professionals that have reached a certain degree of impact, at least at regional level. This study therefore mimics the barriers encountered by lymphoedema patients seeking healthcare providers with the support of online search engines but might not be exact concerning the current local healthcare measures provided by the communities.

\section{Language bias}

Considering the language barrier, the analysis was limited to six languages spoken by the main authors. Regions of the world not using the latin alphabet were impermeable to our search thus creating false negatives mainly in the data on Asia and North Africa. Therefore, although our search was thoroughly performed with the name of every single country in the world, the fact that we were using western languages in our search reduced our scope of investigation extensively, especially considering that Asia is an extremely populated region of the world. Retrospectively, most countries failing to provide any online information were small in size and population. Additionally, some of these countries use specific local terms to name lymphoedema. Common synonyms are "big foot" in Haiti [29] or "mossy foot" in Ethiopia [38] (Table 5). These alternative terms might have led to incomplete listing of involved professionals in the respective regions of Africa, Central America and Asia.

\section{Importance of developing adequate training offers}

General analysis of the absolute number of professionals qualified at tertiary level in this field reveals a great need 
Table 2 Overview of the leading countries and ratios per continent of professionals, physicians, researchers and societies

\begin{tabular}{|c|c|c|c|c|c|c|c|}
\hline & Professionals & Physicians & Researchers & $\begin{array}{l}\text { Professionals/ } \\
\text { population } \\
\text { (per million) }\end{array}$ & $\begin{array}{l}\text { Physicians/ } \\
\text { population } \\
\text { (per million) }\end{array}$ & $\begin{array}{l}\text { Researchers/ } \\
\text { population } \\
\text { (per million) }\end{array}$ & $\begin{array}{l}\text { Societies/ } \\
\text { Population } \\
\text { (per million) }\end{array}$ \\
\hline Europe & Germany & Germany & UK & Switzerland & Switzerland & Belgium & Switzerland \\
\hline Highest quantity / ratio & 432 & 421 & 79 & 13.80 & 10.74 & 5.70 & 6.22 \\
\hline Population (in million) & 80.9 & 80.9 & 64.5 & 8.2 & 8.2 & 11.2 & 8.2 \\
\hline North America & USA & USA & USA & Grenada & Grenada & Grenada & Grenada \\
\hline Highest quantity / ratio & 241 & 75 & 148 & 47.01 & 18.81 & 28.21 & 9.40 \\
\hline Population (in million) & 318.9 & 318.9 & 318.9 & 0.1 & 0.1 & 0.1 & 0.1 \\
\hline South America & Argentina & Argentina & Brazil & Argentina & Argentina & Guiana & Bermuda \\
\hline Highest quantity / ratio & 181 & 168 & 15 & 4.21 & 3.91 & 2.62 & 15.34 \\
\hline Population (in million) & 43.0 & 43.0 & 206.0 & 43.0 & 42.0 & 0.7 & 0.1 \\
\hline Oceania & Australia & Australia & Australia & Amer. Samoa & Amer. Samoa & Amer. Samoa & Tuvalu \\
\hline Highest quantity / ratio & 80 & 10 & 70 & 162.36 & 18.04 & 144.32 & 101.08 \\
\hline Population (in million) & 23.5 & 23.5 & 23.5 & 0.1 & 0.1 & 0.1 & $<0.1$ \\
\hline Asia & Japan & India & Japan & Micronesia & Japan & Micronesia & Micronesia \\
\hline Highest quantity / ratio & 138 & 102 & 78 & 9.61 & 0.47 & 9.61 & 9.61 \\
\hline Population (in million) & 127.1 & 1295.3 & 127.1 & 0.1 & 127.1 & 0.1 & 0.1 \\
\hline Africa & Nigeria & Cameroon & Nigeria & Sao Tome & Comoros & Sao Tome & Sao Tome \\
\hline Highest quantity / ratio & 76 & 3 & 72 & 21.47 & 2.60 & 21.47 & 10.73 \\
\hline Population (in million) & 177.5 & 22.8 & 177.5 & 0.2 & 0.8 & 0.2 & 0.2 \\
\hline
\end{tabular}

for Asian, North American and European countries to organise training offers. In the reminiscent regions, countries do not seem to possess enough professionals to offer the whole spectrum of medical training on lymphatic diseases (Fig. 2; Table 3). Therefore, it is paramount that healthcare providers in Asia, North America and Europe embrace this challenge, take responsibility and promote training offers to improve global geographical coverage. Lymphology should already be taught in undergraduate medical school in order to close the knowledge gap [11]. Analysing general medical care in most countries of Africa shows that although this continent is responsible for $24 \%$ of the burden of diseases worldwide, it is only disserved by $3 \%$ of the total healthcare providers [39]. One could postulate that if financial resources invested in humanitarian treatment of disease in developing countries in the past had instead been used for medical training, the present situation might not be as unbalanced. In these countries, in spite of an established prevalence of 40 million patients affected with lymphoedema as a consequence of lymphatic filariasis, few are able to receive proper medical support and treatment $[9,10,40]$, especially as the patients are more likely to get the disease if they have a low or medium socioeconomic status and might therefore not be able to afford treatments [41, 42]. On the other hand, the treatment of filariasis constitutes one of the success stories of mass drug administration (Global Programme to
Eliminate Lymphatic Filariasis - GPELF) with decreased primary infections following the global programs of eradication [43]. Community healthcare workers carried out the pharmacologically driven programs. Nevertheless, healthcare workers were not specifically informed about lymphoedema and lacked the clinical expertise of tertiary level professionals to diagnose this condition as a possible corollary of filaria infection. This constituted a lost opportunity of broad geographic impact perpetuating inadequate management, poor treatment and failure to meet the specific needs of patients with lymphoedema after filarial infection [26, 27, 31, 44, 45]. But, even so, substantial health and economic benefits have risen from the program, especially in what concerns lymphoedema prevention by treating the causal worm [42]. National strategies are often followed by new investments. The government of Ethiopia just recently invested in the fight against neglected tropical diseases (including lymphoedema/podoconiosis) in order to achieve the goal of eliminating these until 2020 according to a set up national plan [45]. An important addition to national strategies would be to collect statistical data on the current prevalence of the disease and apply epidemiologic information in the creation of medical support where help is needed $[46,47]$.

The heterogeneity of medical training is not restricted to developing countries. A lack of specialised physicians especially exists in poorer, more rural and remote areas 


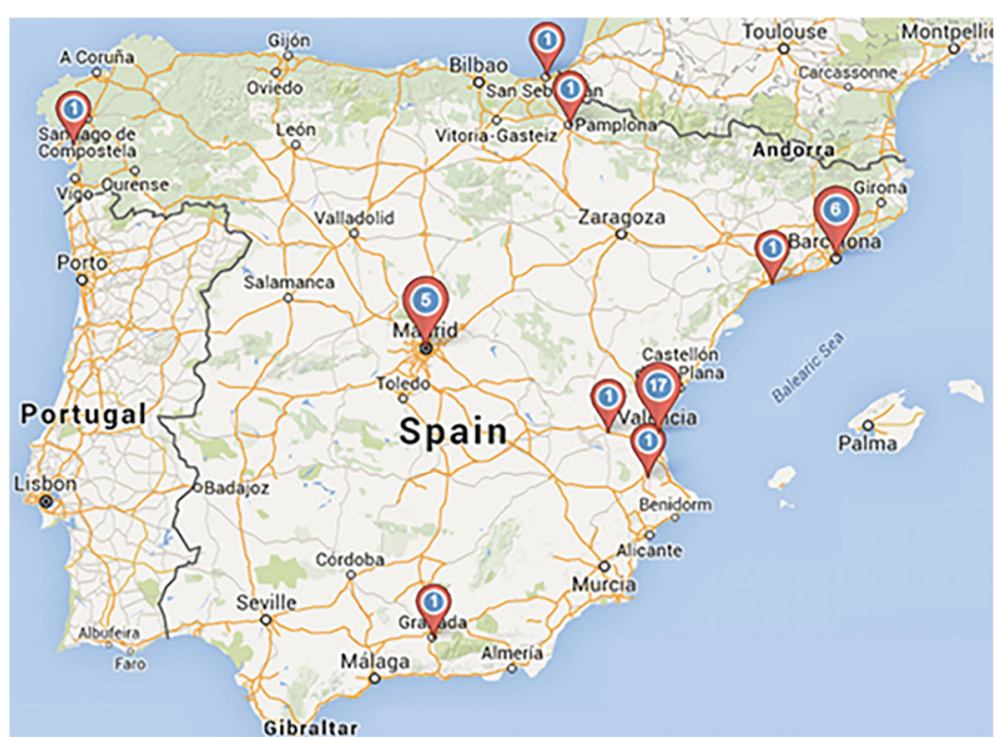

Fig. 4 Geographical distribution of physicians in Spain in absolute numbers

as described for Australia [48] and similar findings were postulated even across the U.K. [8]. In the case of Spain, most mapped physicians were located in cities. Lymphoedema consultation services are mostly based in hospitals and for public insurance patients the access is restricted, making it more difficult to seek qualified treatment [8]. With the exception of some regions of Germany and Switzerland, professionals specialised in lymphatic diseases were very seldom general practitioners, rendering this distributary problem a characteristic of most countries worldwide.

\section{Lymphoedema researchers}

Regarding the data on the number of researchers dedicated to lymphoedema, one of our main difficulties during our search was to identify if these professionals were physicians, or belonged to other professional branches e. g. biologists. Nevertheless, this academic distinction has little influence on the capacity of researching solutions for a disease, as this plurality might be beneficiary for innovation. Most researchers originate from continents with developed countries such as Oceania or Europe. Awareness and public funding of research are still low on upcoming continents such as South Asia although things have started to change [49]. Young researchers are less attracted to investigate a field they have never heard about as most of their universities have failed to include lymphatic diseases in the university curricula. An important milestone of a global strategy to address the problem of medical care of lympho-vascular diseases should also include measures to break the vicious circle of the lack of research. This has to be achieved outside of the laboratories at sub graduate level through innovative training offers.

\section{Professional societies including lymphatic diseases in their topics of interest}

Patients trying to find qualified medical healthcare professionals online, will be confronted with similar limitations encountered in this study. Nevertheless, patients express a deep need for guidance and information [50]. A medical doctor with expertise in lymphatic diseases

Table 3 Distribution of physicians' specialties in the field of lymphology according to continent

\begin{tabular}{|c|c|c|c|c|c|c|}
\hline & Surgery & Conservative Therapy & Medical Imaging & Filaria & Podoconiosis & Research \\
\hline Africa & 8 & 3 & 0 & 4 & 0 & 16 \\
\hline Asia & 139 & 28 & 27 & 21 & 0 & 163 \\
\hline Oceania & 6 & 5 & 0 & 5 & 0 & 21 \\
\hline Europe & 295 & 535 & 25 & 5 & 1 & 234 \\
\hline North America & 68 & 36 & 10 & 4 & 0 & 68 \\
\hline South America & 61 & 34 & 2 & 1 & 1 & 5 \\
\hline Total & 577 & 641 & 64 & 40 & 2 & 507 \\
\hline
\end{tabular}

The highest numbers of physicians' specialists of each continent are marked bold 
Table 4 Overview of societies, institutions and industry specialised in lymphatic diseases per continent including leading countries

\begin{tabular}{lllllll}
\hline & Europe & North America & South Amercia & Africa & Asia & Oceania \\
\hline $\begin{array}{l}\text { Professional societies } \\
\text { and institutions }\end{array}$ & 598 & 218 & 54 & 138 & 319 & 75 \\
$\quad$ Leading country & Germany: 88 & USA: 161 & Argentina: 33 & Ethiopia: 16 & India: 96 & Australia: 31 \\
$\begin{array}{l}\text { Industry } \\
\text { Leading country }\end{array}$ & 90 & 49 & none & 3 & 6 & 2 \\
& UK: 33 & USA: 42 & none & Kenya, Tanzania, & Taiwan: 3 & Australia: 2 \\
\hline
\end{tabular}

that cannot be found by patients searching online is equivalent to a very localised resource. Therefore, we also analysed the number of professional societies, as they play a paramount role in providing information on the spectrum of expertise of their members. Physicians were easily found in South America as the PanAmerican Society for Lymphology and Phlebology published a list of physicians. Other examples of societies providing well-structured information are to be found in Germany and Switzerland. There was no clear correlation between the number of professionals specialised in lymphology in a region or country, and the number of professional societies active in this field. But most problematic was the complete lack of independent societies for lymphatic diseases in most countries of the world that could contribute to high level postgraduate education and facilitate discussions about diagnosis and treatment guidelines.

\section{Industrial activities in lymphology}

In our analysis of the distribution of industrial activity connected to lymphoedema, North America and Europe were the leading continents. The associated industry is currently not pharmaceutical but mainly biotechnological focussing on measurement devices, surgery microscopes and compression garments. Similarly to pharmaceutical companies, biotechnology companies show less interest in e.g. Africa or South America most likely due to poor distribution networks and low profit margins.

\section{Additional policies for palliation of current deficits}

It is somewhat striking to see this disparity of numbers of specialised physicians in developed countries. We believe the reasons for their relatively high number in some countries as e.g. Belgium or Germany to be historical. The first lymphoedema clinic was founded in Germany and already in the late seventies, German healthcare insurances started reimbursing lymphoedema therapy modalities. Although many physiotherapists in Germany are trained in manual lymphatic drainage, only medical doctors are entitled to prescribe it. Therefore, there is a positive peer pressure between both professional groups. This leads to some degree of medical training in this field [51], mostly of general physicians as well as doctors in physical and rehabilitation medicine [52]. Why do other developed countries with a similar number of lymphedema patients still lack specialised human health resources? Improving the quality of management of this disease in Germany and the Benelux was not solely due to medical professionals in itself but

Table 5 Overview of local dialect terms and their medical translation for symptoms of lymphatic diseases

\begin{tabular}{|c|c|c|}
\hline Local term & General term & Country \\
\hline Gwo pye (Creol dialect) or big foot & Elephantiasis & Haiti [29] \\
\hline Maklouklou or gwo gren & Hydrocele & Haiti [29] \\
\hline Dicipela & Erysipela & Dominican Republic $[26,32]$ \\
\hline Seca & Large boil in the groin or upper thigh & Dominican Republic $[26,32]$ \\
\hline Mossy foot & Podoconiosis & Ethiopia [38] \\
\hline Biaye or edoa & Inguinal lymphadenitis & Ghana [30] \\
\hline Ahu par or esam & $\begin{array}{l}\text { Fever with chills and rigors accompanied by } \\
\text { swollen groin glands and legs }\end{array}$ & Ghana [30] \\
\hline $\begin{array}{l}\text { Gyepim, dubah (both in Ahanta } \\
\text { and Nzema dialect) } \\
\text { or large leg }\end{array}$ & Elephantiasis & Ghana [30] \\
\hline $\begin{array}{l}\text { Etow (Ahanta), wheba (Ahanta), } \\
\text { tuekeh (Nzema) or edoma holokpoo }\end{array}$ & Hydrocele & Ghana [30] \\
\hline Yanaikkal & Lymphoedema or elephantiasis of the lower leg & India [56] \\
\hline Veraveekkam or veravadam & Hydrocele & India [56] \\
\hline
\end{tabular}


mostly to the professional group of the physiotherapists. Here, reimbursement of lymphoedema treatment was adequate, but only allowed to those physiotherapists having undergone validated specialised training. This motivating restriction never happened in the medical profession. The medical chamber of doctors in Germany failed until now to recognise a medical subspecialty in lymphatic diseases, although reiterated proposals have been delivered by professional societies since the nineties. Until today, all physicians are entitled to manage lymphoedema patients. Also, the reimbursement for this medical act is very low and calculated for periods of three months regardless of the number of times the patient has to be seen in that time interval, leading to low motivation to treat this chronic disease. Paradoxically, European policy makers do not seem to be aware of the costs of fail prescriptions and poor management.

In the U.S. severe reimbursement barriers still exist for lymphatic diseases $[18,53]$. Here, not only direct costs, but also travel costs and loss of earning prohibit patients to seek proper medical treatment $[25,54]$.

Interestingly, in the U.K., where the number of medical doctors specialised in this field is also below demand, nurses established a culture of lymphoedema treatment based on patient self-management and training of family members to provide lymphatic drainage. Showing patients how to manage their lymphoedema reduces exacerbations and improves their quality of life $[24,55]$. Therefore, it is not neutral to decide which professionals will become key players in this field. It is not sufficient to limit the reimbursement to certified professionals, but special incentives for patient training and empowerment should also be promoted. They eventually increase the patients' independence from the same providers of care that are so scarce in most health systems.

\section{Conclusions}

Lymphoedema patients oftentimes experience a chaotic journey from diagnosis to treatment due to scarce support by the medical system. The time prior to diagnosis and thereafter prior to health reimbursement must be shortened. Interventions in this health sector would ideally be based on the knowledge of the extent of the problem. The present study represents a first attempt to quantify a group of professionals characterised by a deficiency of data. Not only the medical expertise in lymphology is not officially recognised as a subspecialty (except for the Netherlands and the United Kingdom) and experts are therefore not listed as such in the corresponding professional chambers, but also the number of professionals specifically offering health services in this field is globally very limited. With the right policies, as certification and homologation of knowledge at tertiary level, restriction of patient care solely to specialised healthcare providers, structured reimbursement and sufficient research funding, the current situation can be improved. Targeted incentives for medical professionals trained in this field would then ameliorate the management of these diseases, optimise the use of already available financial resources, promote the passage of knowledge and skills in universities, promote research, empower patients and influence interdisciplinary work. These professionals can potentially become the true motors of a worldwide solution. The authors of the study strongly support the use of their database for further research according to the principles of share of good practice.

Abbreviations

ppm: Parts per Million; WHO: World Health Organization

Acknowledgements

We would like to thank David Beverungen for his support in technical issues.

Funding

This work was supported by the European Union [527658 - LLP-1-2012-1DE-ERASMUS-ESMO]. Henrike Schulze, Marisa Nacke and Catarina Hadamitzky were co-financed by this institution. This study presents the work of independent scientists and does not necessarily reflect the views of the European Commission or its services.

Availability of data and materials

Data can be shared upon contact with the senior author.

\section{Authors' contributions}

HS carried out the data gathering and analysis and wrote the manuscript. $\mathrm{MN}$ contributed to the design of figures and tables and provided comments on all drafts. CG provided comments on the draft. CH supervised the study, substantially contributed to data analysis and interpretation and revised all drafts. All authors read and approved the final manuscript.

Ethics approval and consent to participate Not applicable.

\section{Competing interests}

We confirm that this manuscript describes original work and has neither been published elsewhere nor is under consideration by any other journal. All authors have approved the manuscript and agree with its submission to Health Economics Review. The study authors have no competing interests.

\section{Publisher's Note}

Springer Nature remains neutral with regard to jurisdictional claims in published maps and institutional affiliations.

\section{Author details}

'Clinic of Rehabilitation Medicine, Hannover Medical School, Carl-Neuberg-Straße 1, 30625 Hannover, Germany. ${ }^{2}$ Cancer Research UK, Beatson Institute, Glasgow, UK. ${ }^{3}$ Practice for Lympho-Vascular Diseases, Bahnhofstraße 12, Hannover, Germany.

Received: 1 October 2017 Accepted: 3 April 2018

Published online: 16 April 2018

\section{References}

1. Földi M, Földi E. Földi's textbook of lymphology for physicians and Lymphoedema therapists. 3rd rev ed. München: Urban \& Fischer; 2012.

2. Cano J, Rebollo MP, Golding N, Pullan RL, Crellen T, Soler A, et al. The global distribution and transmission limits of lymphatic filariasis: past and present. Parasit Vectors. 2014;7:466. 
3. Wynd S, Melrose WD, Durrheim DN, Carron J, Gyapong M. Understanding the community impact of lymphatic filariasis: a review of the sociocultural literature. Bull World Health Organ. 2007:85:493-8.

4. Szuba A, Rockson SG. Lymphedema: classification, diagnosis and therapy. Vasc Med. 1998;3:145-56.

5. Cormier JN, Askew RL, Mungovan KS, Xing Y, Ross MI, Armer JM. Lymphedema beyond breast cancer: a systematic review and meta-analysis of cancer-related secondary lymphedema. Cancer. 2010;116:5138-49.

6. Ozaslan C, Kuru B. Lymphedema after treatment of breast cancer. Am J Surg. 2004;187:69-72.

7. Lawton G, Rasque H, Ariyan S. Preservation of muscle fascia to decrease lymphedema after complete axillary and ilioinguinofemoral lymphadenectomy for melanoma. J Am Coll Surg. 2002;195:339-51.

8. Moffatt CJ, Franks PJ, Doherty DC, Williams AF, Badger C, Jeffs E, et al. Lymphoedema: an underestimated health problem. QJM - Mon J Assoc Phys. 2003;96:731-8.

9. Yahathugoda TC, Wickramasinghe D, Weerasooriya MV, Samarawickrema WA. Lymphoedema and its management in cases of lymphatic filariasis: the current situation in three suburbs of Matara, Sri Lanka, before the introduction of a morbidity-control programme. Ann Trop Med Parasitol. 2005:99:501-10.

10. Stout NL, Brantus P, Moffatt C. Lymphoedema management: an international intersect between developed and developing countries. Similarities, differences and challenges. Glob Public Health. 2012;7:107-23.

11. Vuong D, Nguyen M, Piller N. Medical education: a deficiency or a disgrace. J Lymphoedema. 2011;6:44-9.

12. Morgan PA, Murray S, Moffatt CJ, Honnor A. The challenges of managing complex lymphoedema/chronic oedema in the UK and Canada. Int Wound J. 2012;9:54-69.

13. Davies R, Fitzpatrick B, Neill AO, Sneddon M. Lymphoedema education needs of clinicians: a national study. J Lymphoedema. 2012;7:14-24.

14. Bogan LK, Powell JM, Dudgeon BJ. Experiences of living with non-cancerrelated lymphedema: implications for clinical practice. Qual Health Res. 2007;17:213-24.

15. Williams AF, Moffatt CJ, Franks PJ. A phenomenological study of the lived experiences of people with lymphoedema. Int J Palliat Nurs. 2004; 10:279-86.

16. Leard T, Barrett C. Successful Management of Severe Unilateral Lower Extremity Lymphedema in an outpatient setting. Phys Ther. 2015;95: 1295-306.

17. Wang W, Keast DH. Prevalence and characteristics of lymphoedema at a wound-care clinic. J Wound Care. 2016:25:S11-2, S14-5.

18. Armer J, Feldman J, Fu M, Stout N, Lasinski B, Tuppo C, et al. ALFP: identifying issues in lymphoedema in the US. J Lymphoedema. 2009;4:3-9.

19. Suma TK, Shenoy RK, Kumaraswami V. A qualitative study of the perceptions, practices and socio-psychological suffering related to chronic brugian filariasis in Kerala, southern India. Ann Trop Med Parasitol. 2003;97: 839-45

20. Bartlett J, Deribe K, Tamiru A, Amberbir T, Medhin G, Malik M, et al. Depression and disability in people with podoconiosis: a comparative crosssectional study in rural northern Ethiopia. Int Health. 2016:8:124-31.

21. Penha TR, Botter B, Heuts EM, Voogd AC, von Meyenfeldt MF, van der Hulst. Quality of life in patients with breast Cancer-related lymphedema and reconstructive breast surgery. J Reconstr Microsurg. 2016;32:484-90.

22. Becker C, Assouad J, Riquet M, Hidden G. Postmastectomy lymphedema: long-term results following microsurgical lymph node transplantation. Ann Surg. 2006;243:313-5.

23. Morgan PA, Franks PJ, Moffatt CJ. Health-related quality of life with Iymphoedema: a review of the literature. Int Wound J. 2005;2:47-62.

24. Stillwaggon E, Sawers L, Rout J, Addiss D, Fox L. Economic costs and benefits of a community-based lymphedema management program for lymphatic Filariasis in Odisha state, India. Am J Trop Med Hyg. 2016;95:877-84.

25. Stanton MC, Best A, Cliffe M, Kelly-hope L, Biritwum NK, Batsa L, et al. Situational analysis of lymphatic filariasis morbidity in Ahanta West District of Ghana. Tropical Med Int Health. 2016;21:236-44.

26. Person B, Addiss D, Bartholomew LK, Meijer C, Pou V, Gonzálvez G, et al. A qualitative study of the psychosocial and health consequences associated with lymphedema among women in the Dominican Republic. Acta Trop. 2007;103:90-7.

27. Rath K, Swain BK, Mishra S, Patasahani T, Kerketta AS, Babu BV. Peripheral health workers' knowledge and practices related to filarial lymphedema care: a study in an endemic district of Orissa, India. Am J Trop Med Hyg 2005;72:430-3.

28. Pushter J, Stewart R. Smartphone ownership and internet usage continues to climb in emerging economies. Pew Research Center. 2016. http://www. pewglobal.org/2016/02/22/internet-access-growing-worldwide-but-remainshigher-in-advanced-economies/ Accessed 23 Feb 2018.

29. Coreil J, Mayard G, Louis-Charles J, Addiss D. Filarial elephantiasis among Haitian women: social context and behavioural factors in treatment. Tropical Med Int Health. 1998;3:467-73.

30. Ahorlu CK, Dunyo SK, Koram KA, Nkrumah FK, Aagaard-Hansen J, Simonsen PE. Lymphatic filariasis related perceptions and practices on the coast of Ghana: implications for prevention and control. Acta Trop. 1999:73:251-61.

31. Richard SA, Mathieu E, Addiss DG, Sodahlon YK. A survey of treatment practices and burden of lymphoedema in Togo. Trans R Soc Trop Med Hyg. 2007;101:391-7.

32. Person B, Addiss DG, Bartholomew LK, Meijer C, Pou V, van den Borne B. Health-seeking behaviors and self-care practices of Dominican women with lymphoedema of the leg: implications for lymphoedema management programs. Filaria J. 2006;5:13.

33. Babington LM, Kelley BR, Patsdaughter CA, Soderberg RM, Kelley JE. From recipes to recetas: health beliefs and health care encounters in the rural Dominican Republic. J Cult Divers. 1999;6:20-5.

34. Aarons DE. Medicine and its alternatives. Health care priorities in the Caribbean. Hast Cent Rep. 1999:29:23-7.

35. Bandyopadhyay L. Lymphatic filariasis and the women of India. Soc Sci Med. 1996;42(10):1401.

36. Cassidy T, Worrell CM, Little K, Prakash A, Patra I, Rout J, et al. Experiences of a community-based lymphedema management program for lymphatic Filariasis in Odisha state, India: an analysis of focus group discussions with patients, families, community members and program volunteers. PLoS Negl Trop Dis. 2016;10:e0004424.

37. Pachter LM. Culture and Clinical care. Folk illness beliefs and behaviors and their implications for health care delivery. JAMA. 1994;271:690-4.

38. Davey G, Burridge E. Community-based control of a neglected tropical disease: the mossy foot treatment and prevention association. PLoS Negl Trop Dis. 2009;3:e424.

39. International Finance Corporation WBG. The business of health in Africa partnering with the private sector to improve People's lives. Washington DC 2008.

40. Addiss DG, Brady MA. Morbidity management in the global Programme to eliminate lymphatic Filariasis: a review of the scientific literature. Filaria J. 2007;6:2.

41. Mutheneni SR, Upadhyayula SM, Kumaraswamy S, Kadiri MR, Nagalla B. Influence of socioeconomic aspects on lymphatic filariasis: a case-control study in Andhra Pradesh, India. J Vector Borne Dis. 2016;53:272-8.

42. Turner HC, Bettis AA, Chu BK, McFarland DA, Hooper PJ, Ottesen EA, et al. The health and economic benefits of the global programme to eliminate lymphatic filariasis (2000-2014). Infect Dis Pov. 2016:5:54.

43. Omura S, Crump A. The life and times of ivermectin - a success story. Nat Rev Microbiol. 2004;2:984-9.

44. Schellekens SM, Ananthakrishnan S, Stolk WA, Habbema JDF, Ravi R. Physicians' management of filarial lymphoedema and hydrocele in Pondicherry, India. Trans R Soc Trop Med Hyg. 2005;99:75-7.

45. Mengitsu B, Shafi O, Kebede B, Kebede F, Worku DT, Herero M. Ethiopia and its steps to mobilize resources to achieve 2020 elimination and control goals for neglected tropical diseases webs joined can tie a lion. Int Health. 2016;8(Suppl 1):i34-52.

46. Cooper G, Bagnall A. Prevalence of lymphoedema in the UK: focus on the southwest and West Midlands. Br J Commun Nurs. 2016;Suppl: S6-14.

47. Yimer M, Hailu T, Mulu W, Abera B. Epidemiology of elephantiasis with special emphasis on podoconiosis in Ethiopia: a literature review. J Vector Borne Dis. 2015:52:111-5.

48. Wakerman J, Humphreys JS, Wells R, Kuipers P, Entwistle P, Jones J. Primary health care delivery models in rural and remote Australia: a systematic review. BMC Health Serv Res. 2008;8:276.

49. Sadana R, D'Souza C, Hyder AA, Chowdhury AMR. Importance of health research in South Asia. BMJ. 2004;328:826-30.

50. Bulley C. Making a case for funding for lymphoedema services. J Lymphoedema. 2007;2:22-9. 
51. Ärztekammer Westfalen-Lippe. Curriculäre Fortbildung Lymphologie für Ärzte/innen". https://www.aekwl.de/index.php?id=5557. Accessed 23 Feb 2018.

52. Fialka-Moser V, Korpan M, Varela E, Ward A, Gutenbrunner C, Casillas JM, et al. The role of physical and rehabilitation medicine specialist in lymphoedema. Ann Phys Rehabil Med. 2013;56:396-410.

53. Shaitelman SF, Cromwell KD, Rasmussen JC, Stout NL, Armer JM, Lasinski BB, et al. Recent progress in the treatment and prevention of cancer-related lymphedema. CA Cancer J Clin. 2015;65:55-81.

54. Ramaiah KD, Radhamani MP, John KR, Evans DB, Guyatt H, Joseph A. The impact of lymphatic filariasis on labour inputs in southern India: results of a multi-site study. Ann Trop Med Parasitol. 2000;94:353-64.

55. Lu S-R, Hong R-B, Chou W, Hsiao P-C. Role of physiotherapy and patient education in lymphedema control following breast cancer surgery. Ther Clin Risk Manag. 2015;11:319-27.

56. Ramaiah KD, Kumar KN, Ramu K. Knowledge and beliefs about transmission, prevention and control of lymphatic filariasis in rural areas of South India. Tropical Med Int Health. 1996;1:433-8.

\section{Submit your manuscript to a SpringerOpen ${ }^{\circ}$ journal and benefit from:}

- Convenient online submission

- Rigorous peer review

- Open access: articles freely available online

- High visibility within the field

- Retaining the copyright to your article

Submit your next manuscript at $\gg$ springeropen.com 